Acta Crystallographica Section E

Structure Reports

Online

ISSN 1600-5368

H. S. Yathirajan, ${ }^{a}$ Anil N. Mayekar,, ${ }^{\text {B. Narayana, }}{ }^{\text {B }}$ B. K. Sarojini $^{b}$ and Michael Bolte ${ }^{\mathrm{C}_{*}}$

a Department of Studies in Chemistry, University of Mysore, Manasagangotri, Mysore 570 006, India, 'bepartment of Chemistry, P. A. College of Engineering, Nadupadavu, Mangalore 574 153, India, and ' Institut für Anorganische Chemie, J. W. Goethe-Universität Frankfurt, Max-von-Laue-Strasse 7, 60438 Frankfurt/Main, Germany

Correspondence e-mail:

bolte@chemie.uni-frankfurt.de

\section{Key indicators}

Single-crystal X-ray study

$T=173 \mathrm{~K}$

Mean $\sigma(\mathrm{C}-\mathrm{C})=0.005 \AA$

$R$ factor $=0.039$

$w R$ factor $=0.093$

Data-to-parameter ratio $=16.1$

For details of how these key indicators were automatically derived from the article, see http://journals.iucr.org/e.

\title{
2,3-Dibromo-1-(2,4-dichlorophenyl)-3-(4,5-di- methoxy-2-nitrophenyl)propan-1-one
}

The title compound, $\mathrm{C}_{17} \mathrm{H}_{13} \mathrm{Br}_{2} \mathrm{Cl}_{2} \mathrm{NO}_{5}$, crystallizes with two similar molecules in the asymmetric unit. The $\mathrm{Br}$ atoms are trans to each other.

\section{Comment}

For a structurally simple group of compounds, chalcones display an impressive array of biological activities, among which antimalarial (Liu et al., 2003), antiprotozoal (Nielson et al., 1998), nitric oxide inhibition (Rajas et al., 2002) and anticancer activities (Dinkova-Kostova et al., 1998) have been reported in the literature. Among several organic compounds reported for non-linear optical (NLO) properties, chalcone derivatives are notable materials for their excellent blue light transmittance and good crystallizability. They provide a necessary configuration to show NLO properties, with two planar rings connected through a conjugated double bond (Goto et al., 1991; Uchida et al., 1998; Tam et al., 1989; Indira et al., 2002; Sarojini et al., 2006). The substitution of a bromo group on either of the phenyl rings greatly influences the noncentrosymmetric crystal packing. The bromo group can obviously improve the molecular first-order hyperpolarizabilities and can effectively reduce dipole-dipole interactions between the molecules. Chalcone derivatives usually have a lower melting temperature, which can be a drawback when we use these crystals in optical instruments. Chalcone dibromides usually have higher melting points and are thermally stable. Only a few structures of these compounds have been reported (Butcher et al., 2006; Yathirajan et al., 2007; Harrison et al., 2005). In continuation of our studies of chalcones and their derivatives (Yathirajan et al., 2006, and references therein), the title chalcone dibromide, (I), was prepared by the bromination of the chalcone and its crystal structure is reported.<smiles>COc1cc(C(Br)C(Br)C(=O)c2ccc(Cl)cc2Cl)c([N+](=O)[O-])cc1OC</smiles>

(I)
Received 19 March 2007 Accepted 26 March 2007
The asymmetric unit contains two molecules; a perspective view is shown in Fig. 1. Bond lengths and angles can be regarded as normal [Cambridge Crystallographic Database, Version 5.28, November 2006, updated January 2007 (Allen, 2002); Mogul, Version 1.1 (Bruno et al., 2004)]. The two 
molecules of (I) in the asymmetric unit are very similar: a least-squares fit of all non-H atoms gives an r.m.s. deviation of $0.659 \AA$. The $\mathrm{Br}$ atoms are trans to each other. The nitro groups are slightly twisted out of the plane of the aromatic ring to which they are attached (Table 1).

\section{Experimental}

(2E)-1-(2,4-Dichlorophenyl)-3-(4,5-dimethoxy-2-nitrophenyl)prop2-en-1-one (3.82 g, $0.01 \mathrm{~mol})$ was treated with bromine in acetic acid $(30 \%)$ until the orange colour of the solution persisted. After stirring for half an hour, the contents were poured on to crushed ice. The resulting solid mass was collected by filtration. The compound was dried and recrystallized from ethanol. Crystals of (I) suitable for structure determination were obtained from a solution in an acetone-toluene mixture $(1: 1 \mathrm{v} / \mathrm{v})$ by slow evaporation (yield $85 \%$; m.p. 441-443 K). Analysis for $\mathrm{C}_{17} \mathrm{H}_{13} \mathrm{Br}_{2} \mathrm{Cl}_{2} \mathrm{NO}_{5}$ : found (calculated): C 37.53 (37.67), H 2.38 (2.42), N 2.54\% (2.58\%).

\section{Crystal data \\ $\mathrm{C}_{17} \mathrm{H}_{13} \mathrm{Br}_{2} \mathrm{Cl}_{2} \mathrm{NO}_{5}$ \\ $M_{r}=542.00$ \\ Orthorhombic, $\mathrm{Pbcn}$ \\ $a=13.7847$ (4) ^ \\ $b=18.7740(5) \AA$ \\ $c=29.8756(10) \AA$

$$
\begin{aligned}
& V=7731.6(4) \AA^{3} \\
& Z=16 \\
& \text { Mo } K \alpha \text { radiation } \\
& \mu=4.50 \mathrm{~mm}^{-1} \\
& T=173(2) \mathrm{K}
\end{aligned}
$$$$
0.35 \times 0.32 \times 0.22 \mathrm{~mm}
$$

\section{Data collection}

Stoe IPDSII two-circle diffractometer

Absorption correction: multi-scan (MULABS; Spek, 2003; Blessing, 1995)

$T_{\min }=0.232, T_{\max }=0.388$

\section{Refinement}

$R\left[F^{2}>2 \sigma\left(F^{2}\right)\right]=0.039$

$w R\left(F^{2}\right)=0.093$

$S=1.04$

7902 reflections
114175 measured reflections 7902 independent reflections 6553 reflections with $I>2 \sigma(I)$ $R_{\text {int }}=0.090$

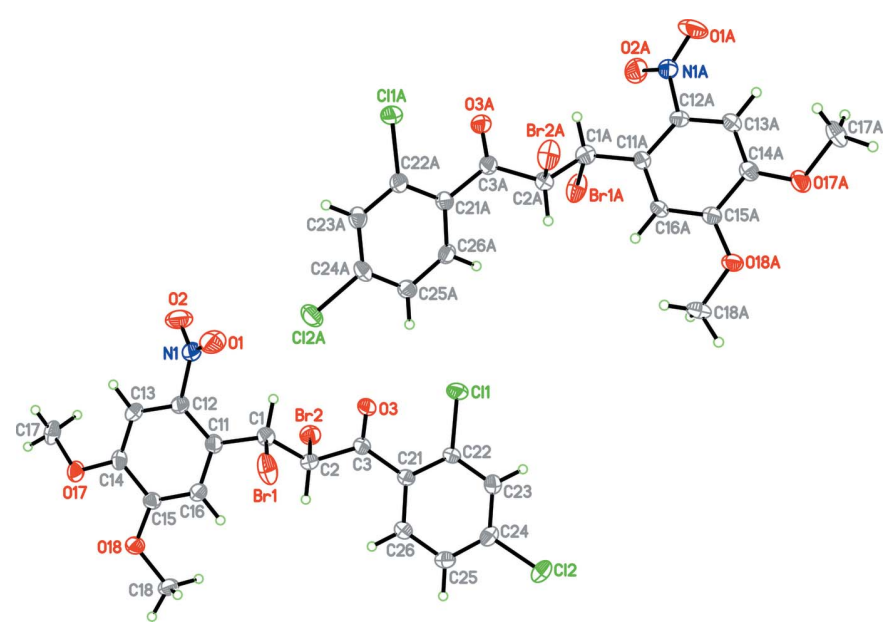

Figure 1

The asymmetric unit of (I), with the atom numbering. Displacement ellipsoids are drawn at the $50 \%$ probability level.

ANM thanks the University of Mysore for permission to carry out the research work.

\section{References}

Allen, F. H. (2002). Acta Cryst. B58, 380-388.

Blessing, R. H. (1995). Acta Cryst. A51, 33-38.

Bruno, I. J., Cole, J. C., Kessler, M., Luo, J., Motherwell, W. D. S., Purkis, L. H., Smith, B. R., Taylor, R., Cooper, R. I., Harris, S. E. \& Orpen, A. G. (2004). J. Chem. Inf. Comput. Sci. 44, 2133-2144.

Butcher, R. J., Yathirajan, H. S., Anilkumar, H. G., Sarojini, B. K. \& Narayana, B. (2006). Acta Cryst. E62, o2525-o2527.

Dinkova-Kostova, A. T., Abey-Gunawardana, C. \& Talalay, P. (1998). J. Med. Chem. 41, 5287-5296.

Goto, Y., Hayashi, A., Kimura, Y. \& Nakayama, M. (1991). J. Cryst. Growth, 108, 688-698.

Harrison, W. T. A., Yathirajan, H. S., Sarojini, B. K., Narayana, B. \& Anilkumar, H. G. (2005). Acta Cryst. C61, o728-0730.

Indira, J., Karat, P. P. \& Sarojini, B. K. (2002). J. Cryst. Growth, 242, 209-214.

Liu, M., Wilairat, P., Cropft, S. L., Tan, A. L. C. \& Go, M. I. (2003). Bioorg. Med. Chem. 11, 2729-2738.

Nielson, S. F., Christensen, S. B., Cruciani, G., Kharazmi, A. \& Liljefors, T. (1998). J. Med. Chem. 41, 4819-4832.

\section{Table 1}

Selected torsion angles $\left({ }^{\circ}\right)$.

\begin{tabular}{llll}
\hline $\mathrm{O} 1-\mathrm{N} 1-\mathrm{C} 12-\mathrm{C} 11$ & $-40.5(5)$ & $\mathrm{O} 2 A-\mathrm{N} 1 A-\mathrm{C} 12 A-\mathrm{C} 11 A$ & $-27.1(6)$ \\
$\mathrm{O} 2-\mathrm{N} 1-\mathrm{C} 12-\mathrm{C} 13$ & $-37.8(5)$ & $\mathrm{O} 1 A-\mathrm{N} 1 A-\mathrm{C} 12 A-\mathrm{C} 13 A$ & $-25.8(6)$
\end{tabular}

$\mathrm{H}$ atoms were found in a difference map but were refined using a riding model, with $\mathrm{C}-\mathrm{H}$ ranging from 0.95 to $1.00 \AA$ and with $U_{\text {iso }}(\mathrm{H})$ $=1.2 U_{\text {eq }}(\mathrm{C})$ or $U_{\text {iso }}(\mathrm{H})=1.5 U_{\text {eq }}\left(\mathrm{C}_{\text {methyl }}\right)$. The methyl groups were allowed to rotate but not to tip. The highest residual electron density peak is located $1.05 \AA$ from atom $\operatorname{Br} 1 A$.

Data collection: $X$-AREA (Stoe \& Cie, 2001); cell refinement: $X$-AREA; data reduction: $X$-AREA; $\operatorname{program}(\mathrm{s})$ used to solve structure: SHELXS97 (Sheldrick, 1997); program(s) used to refine structure: SHELXL97 (Sheldrick, 1997); molecular graphics: XP in SHELXTL-Plus (Sheldrick, 1991); software used to prepare material for publication: SHELXL97.
Rajas, J., Paya, M., Domingues, J. N. \& Ferrandiz, M. L. (2002). Bioorg. Med. Chem. Lett. 12, 1951-1954.

Sarojini, B. K., Narayana, B., Ashalatha, B. V., Indira, J. \& Lobo, K. J. (2006). J. Cryst. Growth, 295, 54-59.

Sheldrick, G. M. (1991). SHELXTL-Plus. Release 4.1. Siemens Analytical $\mathrm{X}$-ray Instruments Inc., Madison, Wisconsin, USA.

Sheldrick, G. M. (1997). SHELXS97 and SHELXL97. University of Göttingen, Germany.

Spek, A. L. (2003). J. Appl. Cryst. 36, 7-13.

Stoe \& Cie (2001). X-AREA. Stoe \& Cie, Darmstadt, Germany.

Tam, W., Guerin, B., Calabrese, J. C. \& Stevenson, S. H. (1989). Chem. Phys. Lett. 154, 93-96.

Uchida, T., Kozawa, K., Sakai, T., Aoki, M., Yoguchi, H., Abduryim, A. \& Watanabe, Y. (1998). Mol. Cryst. Liq. Cryst. 315, 135-140.

Yathirajan, H. S., Ashalatha, B., Narayana, B., Bindya, S. \& Bolte, M. (2006). Acta Cryst. E62, o4551-o4553.

Yathirajan, H. S., Mayekar, A. N., Narayana, B., Sarojini, B. K. \& Bolte, M. (2007). Acta Cryst. E63, o827-o828. 